\title{
The statistical studies of the inner boundary of plasma sheet
}

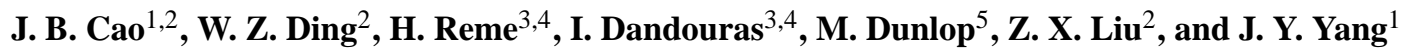 \\ ${ }^{1}$ Beijing University of Aeronautics and Astronautics, 100190, Beijing, China \\ ${ }^{2}$ Key laboratory for space weather/CSSAR, 100190, Beijing, China \\ ${ }^{3}$ University of Toulouse, UPS, CESR, 9 avenue du colonel Roche, 31028, Toulouse Cedex 4, France \\ ${ }^{4}$ CNRS, UMR5187, 31028 Toulouse, France \\ ${ }^{5}$ Rutherford Appleton Laboratory, Didcot OX11 0QX, UK
}

Received: 16 August 2010 - Revised: 26 January 2011 - Accepted: 26 January 2011 - Published: 8 February 2011

\begin{abstract}
The penetration of plasma sheet ions into the inner magnetosphere is very important to the inner magnetospheric dynamics since plasma sheet ions are one of the major particle sources of ring current during storm times. However, the direct observations of the inner boundary of the plasma sheet are fairly rare due to the limited number of satellites in near equatorial orbits outside $6.6 R_{\mathrm{E}}$. In this paper, we used the ion data recorded by TC-1 from 2004 to 2006 to study the distribution of inner boundary of ion plasma sheet (IBIPS) and for the first time show the observational distribution of IBIPS in the equatorial plane. The IBIPS has a dawn-dusk asymmetry, being farthest to the Earth in the 06:00 08:00 LT bin and closest to the Earth in the 18:00-20:00 LT bin. Besides, the IBIPS has also a day-night asymmetry, which may be due to the fact that the ions on the dayside are exposed more time to loss mechanisms on their drift paths. The radial distance of IBIPS decrease generally with the increase of Kp index. The mean radial distance of IBIPS is basically larger than $6.6 R_{\mathrm{E}}$ during quiet times and smaller than $6.6 R_{\mathrm{E}}$ during active times. When the strength of convection electric field increases, the inward shift of IBIPS is most significant on the night side (22:00-02:00 LT). For $\mathrm{Kp} \leq 0^{+}$, only $16 \%$ of IBIPSs penetrate inside the geosynchronous orbit. For $2 \leq \mathrm{Kp}<3^{+}$, however, $70 \%$ of IBIPSs penetrate inside the geosynchronous orbit. The IBIPS has weak correlations with the AE and Dst indexes. The average correlation coefficient between $R_{i}$ and $\mathrm{Kp}$ is -0.58 while the correlation coefficient between $R_{i}$ and AE/Dst is only $-0.29 / 0.17$. The correlation coefficients are local time dependent. Particularly, $R_{i}$ and Kp are highly correlated $(r=-0.72)$ in the night sector, meaning that the radial distance of IBIPS $R_{i}$ in the night sector has
\end{abstract}

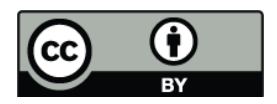

Correspondence to: J. B. Cao

(jbcao@cssar.ac.cn) the good response to the Kp index These observations indicate that $\mathrm{Kp}$ plays a key role in determining the position of IBIPS.

Keywords. Magnetospheric physics (Plasma convection; Plasma sheet; Storms and substorms)

\section{Introduction}

The plasma sheet is the region of closed field lines in the equatorial magnetotail, where the particles are within the region of open electric and magnetic drift paths. Some important substorm and geomagnetic storm phenomena in the inner magnetosphere such as ring currents and particle injections are closely related to the plasma sheet. Therefore the plasma sheet represents an important region in the Earth's magnetosphere and plays a key role in both substorms and geomagnetic storms.

Plasma sheet particles originally come from the solar wind and ionosphere, and are hot, with a typical ion energy of $5-10 \mathrm{keV}$ and electron energy of $1-5 \mathrm{keV}$. Previous studies show that plasma sheet particles are the source of energetic particles that are injected into the inner magnetosphere during magnetic substorms (e.g., McComas et al., 1993; Birn et al., 1997; Kerns et al., 1994; Li et al., 1998; Dandouras et al., 2009a). Furthermore, the plasma sheet is believed to be one of the major particle source for the ring current population (10-200 keV ions and electrons) (Chen et al., 1994; Jordanova et al., 1998; Kozyra et al., 1998; Wang et al., 2008). For this reason many ring current simulations have used the plasma sheet properties as an outer boundary condition for their calculations (Wolf et al., 1982; Chen et al., 1994; Fok et al., 1996; Kozyra et al., 1998; Ebihara et

Published by Copernicus Publications on behalf of the European Geosciences Union. 
al., 2005; Ganushkina et al., 2005; Jordanova and Miyoshi, 2005; Liemohn et al., 2005).

Large scale corotation and convection electric fields, combined with the gradient and curvature of geomagnetic field, make plasma sheet particles to be in continuous drift movement toward and around the Earth with drift velocities that are dependent on their energies and pitch angles. The inner boundary of plasma sheet is just the boundary between open and closed drift path regions, i.e., the Alfvén layer of plasma sheet particles. The locations of the inner boundary of electron plasma sheet, marked by $1 \mathrm{keV}$ electron flux cutoff (Thomsen et al., 2002), is typically located near geosynchronous orbit (Denton et al., 2007). Under conditions of enhanced magnetospheric convection, the inner boundary of ion plasma sheet moves Earthwards and enter the inner magnetosphere, thus allowing the ions from the tail plasma sheet to have access to the inner magnetosphere and to be adiabatically energized to the ring current energy range.

Both theoretical and observational studies have been performed about the penetration of the inner boundary of the plasma sheet into the inner magnetosphere. Maurice et al. (1998) performed a statistical study of the plasma environment in geosynchronous orbit. Korth et al. (1999) applied the conventional particle drift paradigm to the particle observations in geosynchronous orbit and were able to show that a simple parameterization of the convection electric field strength with Kp, together with the concept of Alfvén boundaries, was exceptionally successful in explaining the average plasma sheet access to geosynchronous orbit during both quiet and disturbed times. Friedel et al. (2001) expanded the results of both these previous studies to cover the entire inner magnetosphere using the data from the Polar HYDRA instrument and showed evidence that the same models and assumptions could successfully order the plasma sheet access to the inner zone in a global sense. Wang et al. (2008) showed that the inner edge of the ion plasma sheet near dusk moved from $R=6 R_{\mathrm{E}}$ during the pre-storm quiet time to $R=3.5 R_{\mathrm{E}}$ during the main phase, and then moved outward during the recovery phase. Runov et al. (2008) found that the plasma sheet electron boundary moved inward to $R=4 R_{\mathrm{E}}$ and outward back to $8 R_{\mathrm{E}}$ within about $1 \mathrm{~h}$ during substorms on 23 March 2007. Dandouras et al. (2009) presented the observations by Cluster about the penetration of plasma sheet ions into the ring current region. Up to present, however, the direct observations of the inner boundary of the plasma sheet are fairly rare due to the limited number of satellites in near-equatorial orbits outside $6.6 R_{\mathrm{E}}$ and previous studies have mainly used data from Geosynchronous orbit (Maurice et al., 1998; Korth et al., 1999; Korth and Thomsen, 2001) or the mapped data above equatorial plane (Friedel et al., 2001).

In our work, using the ion data of TC-1 of Double Star Program (DSP) in the inner magnetosphere, we study the distribution of inner boundary of ion plasma sheet (IBIPS) in the equatorial plane and its relations with $\mathrm{Kp}$, Dst and AE indexes. Since previous studies mainly used the data on geosynchronous orbit or the mapped data above equatorial plane, TC- 1 provides an excellent opportunity to study the penetration of ion plasma sheet into the inner magnetosphere, especially outside the geosynchronous orbit.

The paper is organized as follows: the instrumentation is presented in Sect. 2. The case and statistical studies of IBIPS crossing events are presented in Sect. 3. Finally, Sect. 4 shows the conclusions.

\section{Instrumentation}

The TC-1/DSP satellite, a China-ESA cooperation mission, is in an eccentric near equatorial orbit with an apogee radial distance of about $13.4 R_{\mathrm{E}}$, a perigee radial distance of about $6934 \mathrm{~km}$, and an inclination of $28.5^{\circ}$ (Liu et al., 2005). The data of plasma and magnetic field come from the HIA (Hot Ion Analyzer) (Rème et al., 2005) and FGM (Fluxgate Magnetometer) (Carr et al., 2005) on board TC-1 respectively, and are all at a time resolution of $4 \mathrm{~s}$. The HIA instrument on board the TC- 1 spacecraft is an ion spectrometer identical to the HIA sensor of the CIS instrument on board the 4 Cluster spacecraft (Rème et al., 2001). This instrument measures the $3-\mathrm{D}$ distribution functions of the ions between $5 \mathrm{eV} \mathrm{q}^{-1}$ and $32 \mathrm{keV} \mathrm{q}^{-1}$ without mass discrimination. The first-order moments gives the average velocity $V$ of the ions, referred to as the bulk velocity: Converting the momentum flux tensor and the energy flux vector to the frame where the average velocity is zero, one obtains the temperature tensor. The scale temperature is just the trace of temperature tensor (see Rème et al., 2001, 2005). Here all the moments are calculated by integration over the energy range $5 \mathrm{eV}-32 \mathrm{keV}$. The satellite positions are given in Geocentric Solar Magnetospheric (GSM) coordinates throughout this paper.

\section{Observations}

\subsection{Identification of the inner boundary of ion plasma sheet}

In the magnetotail plasma sheet, the energy range of ions is $5-10 \mathrm{keV}$ and of electrons is $1-5 \mathrm{keV}$. In the equatorial plane, from the outside to the inside of the plasma sheet, the ion temperature and the ion flux in the energy range $5-10 \mathrm{keV}$ increase gradually. Since electrons and ions are on different convection paths, the inner boundaries of plasma sheet for ions and electrons are different. The inner boundary of electron plasma sheet is usually determined by a sharp decrease of the $\sim 1 \mathrm{keV}$ electron flux (Thomsen et al., 2002; Runov et al., 2008). The inner boundary of the ion plasma sheet is complex due to opposite drift directions of $\boldsymbol{E} \times \boldsymbol{B}$ and magnetic field gradient/curvature.

In our work, we at first tried to define the inner boundary as a rapid increase of ion flux in the energy range $5-15 \mathrm{keV}$ in the outbound leg of TC-1 or a rapid decrease in the inbound 

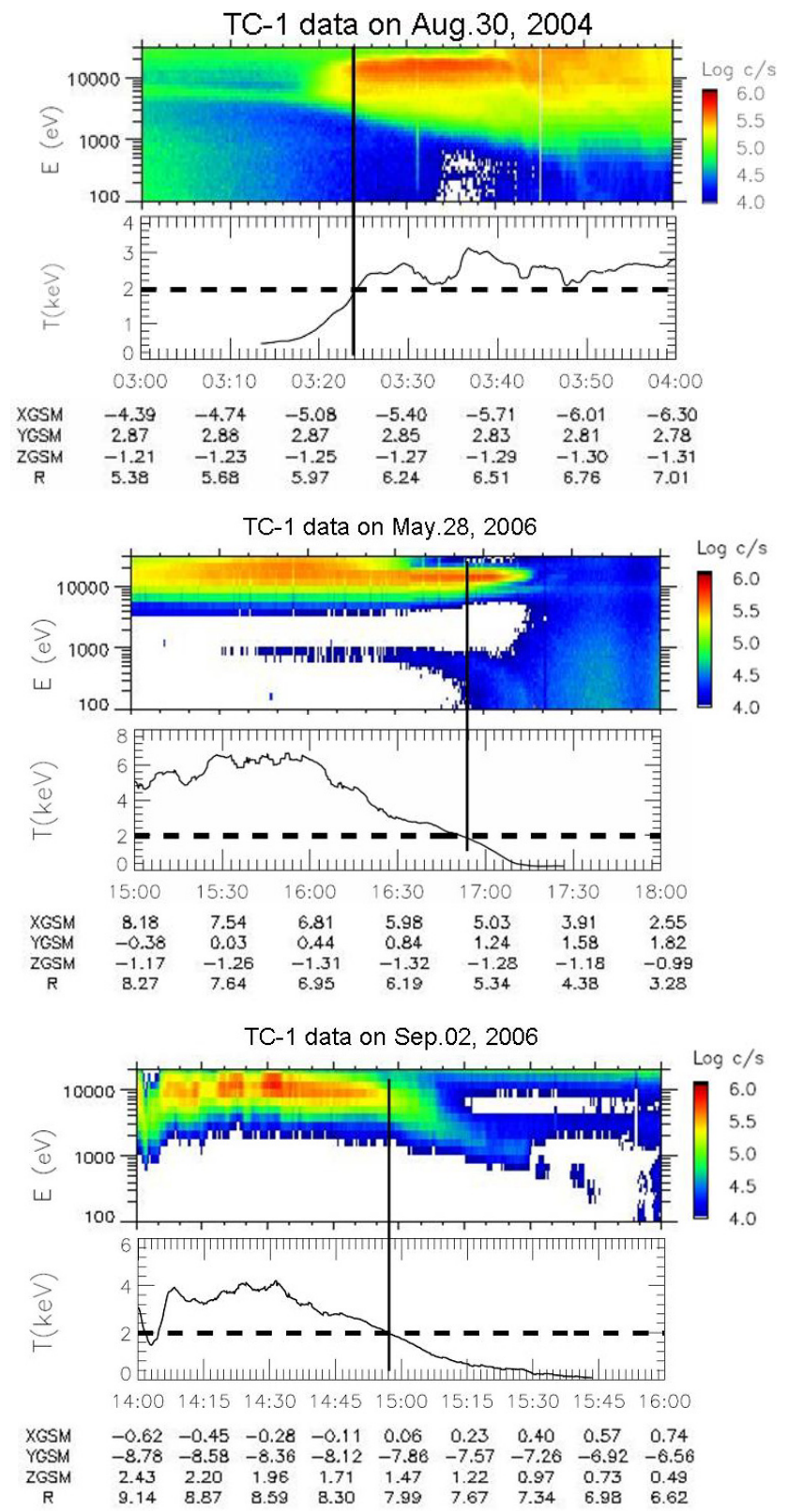

Fig. 1. The ion energy spectrum and ion temperature during three IBIPS crossing events.

leg of TC-1. However, the observations show that the slope of rapid increase of ion flux in the energy range $5-15 \mathrm{keV}$, i.e., the transition layer of IBIPS, corresponds very well to a slop of rapid increase of ion temperature from tens-hundreds $\mathrm{eV}$ to $3-6 \mathrm{keV}$. Since the temperature is readily accessible in the Cluster Active Archive, which greatly facilitates this study, we have chosen to use this criterion to identify the IBIPS. The visual check of the figures displayed in previous papers indicates that the transition layer is $0.2-0.6 R_{\mathrm{E}}$ wide (see Fig. 2 of Wang et al., 2008, and Fig. 2 of Runov et al., 2008). In order to quantitatively study the inner boundary of

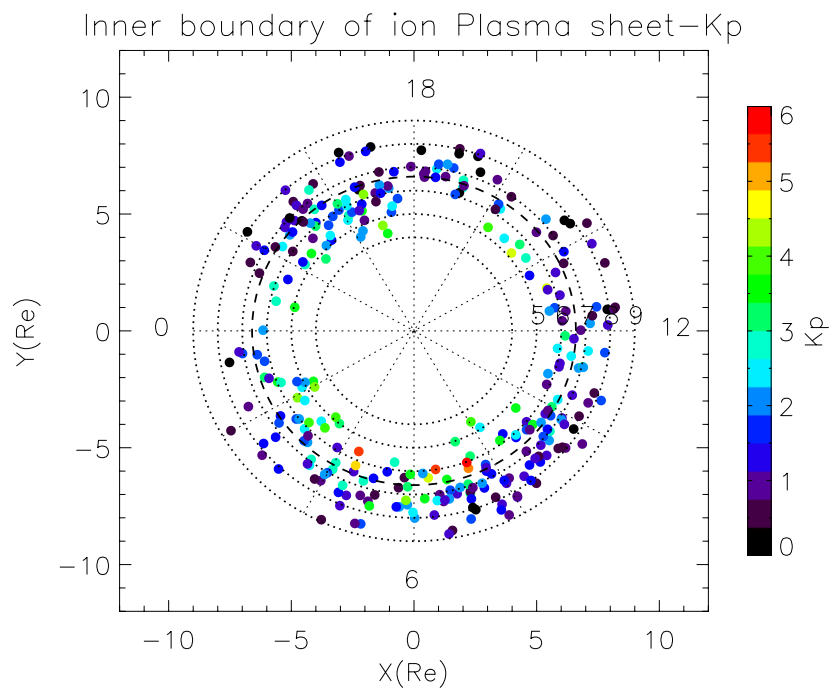

Fig. 2. The scatter plot of inner boundary of ion plasma sheet detected by TC-1 in the X-Y GSM plane color-coded according to Kp index.

the ion plasma sheet, we use a moment parameter, i.e., the ion temperature, to define the inner boundary of the ion plasma sheet. Throughout this paper, the inner boundary of the ion plasma sheet is defined as the point where ion temperature is equal to $2 \mathrm{keV}$ in the slope of rapid increase of temperature which occurs simultaneously with the rapid increase of ion flux in the energy range $5-15 \mathrm{keV}$.

Figure 1 shows the ion energy spectrum and ion temperature in three crossing events of IBIPS. These three crossing events occurred in pre-midnight, post-noon and dawn sectors, respectively. On 30 August 2004, prior to 03:14 UT, the ion temperature is very low and there is almost no hot ions with energy above $1 \mathrm{keV}$. The ion flux with energy above $4 \mathrm{keV}$ began to increase at 03:19 UT (i.e., the color changes from green to red). The ion temperature began to increase rapidly at 03:20 UT and reached $\sim 2.9 \mathrm{keV}$ at 03:25 UT. At 03:24 UT, the temperature reached $2 \mathrm{keV}$. According to the above mentioned criterion for inner boundary of ion plasma sheet, we identified the IBIPS to be located at $(-5.21,2.86$, $-1.25) R_{\mathrm{E}}$, which was crossed by TC-1 at 03:24 UT. The ion temperature shows that the transition layer is from 03:18 UT to $03: 26 \mathrm{UT}$ and is about $0.22 R_{\mathrm{E}}$ thick. It can be seen that the inner boundary of ion plasma sheet defined by the criteria here is located close to the middle of increasing slope of ion temperature or ion flux in the energy range 5-15 keV. During this period, there is a weak substorm which started at 03:15 UT. The crossing of IBIPS occurred in the expansion phase of substorm. At 03:27 UT, the geomagnetic activity is weak with $\mathrm{Kp}=2, \mathrm{AE}=201 \mathrm{nT}$ and Dst $=-13 \mathrm{nT}$. Note that the measurement between 03:00 and 03:10 UT is contaminated by radiation belt particles. 
Table 1. The mean $\left(R_{\mathrm{m}}\right)$ and standard deviation $(\sigma)$ of radial distances of IBIPS in 12 local time bins during quiet times $(\mathrm{Kp}<2)$ and active times $\left(2 \leq \mathrm{Kp} \leq 3^{+}\right)$. The last column shows the difference between two set of mean radial distances $\left(\Delta R_{\mathrm{m}}\right)$ (unit: $R_{\mathrm{E}}$ ).

\begin{tabular}{ccccccc}
\hline LT bins & \multicolumn{2}{c}{$\mathrm{Kp}<2$} & & \multicolumn{2}{c}{$2 \leq \mathrm{Kp} \leq 3^{+}$} & \multirow{2}{*}{$\Delta R_{\mathrm{m}}$} \\
\cline { 2 - 3 } & $R_{\mathrm{m}}$ & $\sigma$ & & $R_{\mathrm{m}}$ & $\sigma$ & \\
\hline 00:00-02:00 & 6.91 & 0.88 & & 5.75 & 0.68 & 1.16 \\
02:00-04:00 & 7.03 & 0.73 & & 6.17 & 0.80 & 0.86 \\
04:00-06:00 & 7.40 & 0.86 & & 6.86 & 0.67 & 0.54 \\
06:00-08:00 & 7.64 & 0.69 & & 6.81 & 0.77 & 0.83 \\
08:00-10:00 & 7.24 & 0.72 & & 6.47 & 0.76 & 0.77 \\
10:00-12:00 & 7.08 & 0.86 & & 6.56 & 0.52 & 0.52 \\
12:00-14:00 & 6.98 & 0.89 & & 6.38 & 0.94 & 0.60 \\
14:00-16:00 & 7.11 & 0.79 & & 6.13 & 0.74 & 0.98 \\
16:00-18:00 & 7.05 & 0.63 & & & & \\
18:00-20:00 & 6.50 & 0.87 & & 5.69 & 0.71 & 0.81 \\
20:00-22:00 & 6.60 & 0.75 & & 5.91 & 0.81 & 0.69 \\
22:00-24:00 & 6.84 & 0.72 & & 5.82 & 0.53 & 1.01 \\
\hline
\end{tabular}

The second crossing event occurred in the noon sector on 28 May 2006. Prior to the crossing time of IBIPS, TC-1 was in the plasma sheet and recorded strong ion flux in the energy range $2-25 \mathrm{keV}$. The ion temperature in the plasma sheet is around $4 \mathrm{keV}$. When TC- 1 exited form plasma sheet, both the ion flux and ion temperature decrease. The ion temperature drops to $2 \mathrm{keV}$ at $16: 50 \mathrm{UT}$. Thus the IPIPS is located at $(5.42,1.10,-1.29) R_{\mathrm{E}}$. The third crossing event occurred in the dawn sector on 2 September 2006. Using the same method, we identified the IBIPS to be located at $(0.08$, $-7.82,1.43) R_{\mathrm{E}}$.

\subsection{Statistical studies}

In this section, based on a dataset of 310 crossings of the inner boundary of the ion plasma sheet of TC-1 from 2004 to 2006, we studied the distribution of inner boundary of ion plasma sheet (IBIPS) in the equatorial plane and its relation with three geomagnetic activity indices $\mathrm{Kp}, \mathrm{AE}$ and Dst.

Figure 2 shows the scatter plot of inner boundary of the ion plasma sheet in the X-Y GSM plane colored according to Kp index. The data in this analysis are clustered around periods of quiet to moderately active times $(0<\mathrm{Kp}<4)$. It can be seen that the IBIPSs are generally located between $R=5 R_{\mathrm{E}}$ and $9 R_{\mathrm{E}}$. The radial distance of IBIPS $R_{i}$ decreases generally with increasing $\mathrm{Kp}$ index, which is consistent with previous observations and with particle drift theory based on Volland-Stern electric field model in the magnetosphere and dipole magnetic field (Volland, 1973; Stern, 1975; Korth et al., 1999). It is easy to understand this result if we consider $\mathrm{Kp}$ as an indicator of convection electric field. Thomsen (2004) pointed out that the increase of strength of convection electric field can result into an increase of $\mathrm{Kp}$. Thus

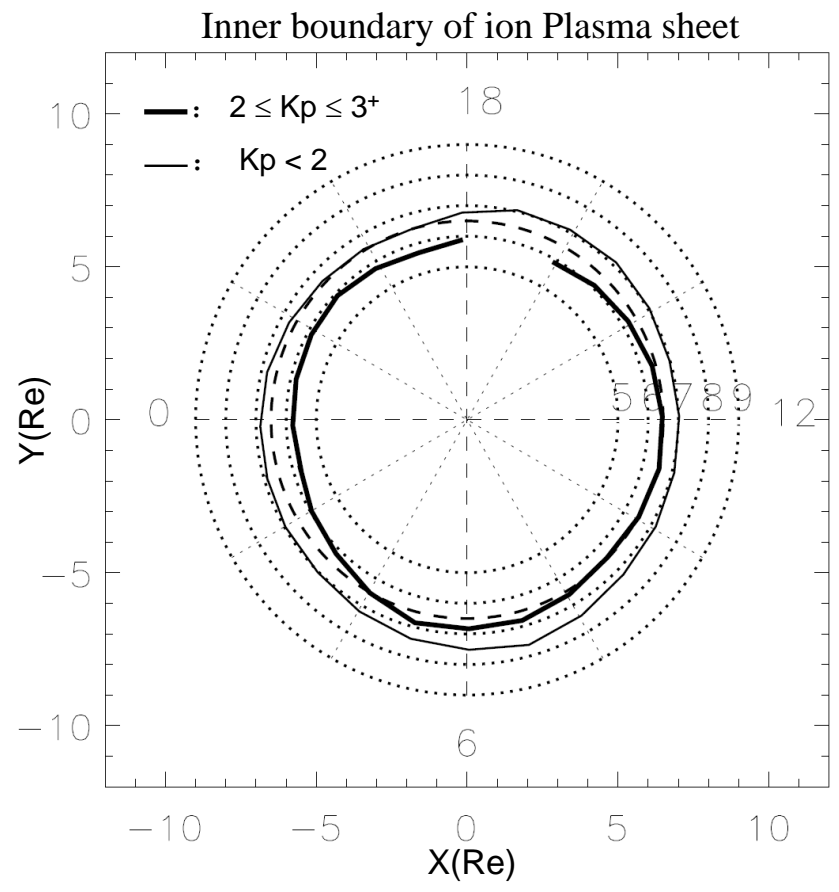

Fig. 3. The mean radial distance of IBIPS for quiet times $(\mathrm{Kp}<2)$ and active times $\left(2 \leq \mathrm{Kp} \leq 3^{+}\right)$.

here the enhanced convection electric field, represented by an increase of $\mathrm{Kp}$, makes plasma sheet ions drift further towards the Earth, making the IBIPS move closer to the Earth. However, the radial distances of IBIPS in Fig. 2 are not completely ordered by Kp index. Some IBISPs have small radial distances even during quiet times when $\mathrm{Kp}$ is small, or vice versa.

Figure 3 shows the distribution of IBIPS in the equatorial plane for quiet times $(\mathrm{Kp}<2)$ and active times $\left(2 \leq \mathrm{Kp} \leq 3^{+}\right)$. The mean $\left(R_{\mathrm{m}}\right)$ and standard deviation $(\sigma)$ of radial distances of IBIPS in 12 local time bins for quiet times and active times are given in Table 1 . The gap in the 16:00-18:00 LT bin for active times is due to the shortage of data. During quiet times, the mean radial distance of IBIPS is basically larger than $6.6 R_{\mathrm{E}}$ with only an exception in the 18:00-20:00 LT bin. An obvious dawn-dusk asymmetry can be clearly seen in Fig. 3. The IBIPSs in the 18:00-20:00 LT bin are closest to the Earth and the mean radial distance in this LT bin is $6.60 R_{\mathrm{E}}$. The IBIPS in the dawn sector (06:0008:00 LT) is farthest to the Earth and the mean radial distance of IBIPS is about $7.64 R_{\mathrm{E}}$. These characteristics are consistent with the Alfvén boundary of plasma sheet ions deduced from particle drift theory. For the protons with an energy above a few $\mathrm{keV}$, their open/closed drift separatrix is closer to the Earth on dusk side than on dawn side (Korth et al., 1999; Ding et al., 2010).

However as seen in Fig. 3, the IBIPSs has also a daynight asymmetry. The mean radial distances of IBIPS in the bins of 16:00-18:00 LT, 14:00-16:00 LT and 12:00-14:00 LT 
Table 2. The penetration ratio $\rho$ of IBIPS inside geosynchronous orbit in four local time sectors for different Kp bins.

\begin{tabular}{lcccc}
\hline LT Sectors & $K=0,0^{+}$ & $1^{-} \leq \mathrm{Kp}<2$ & $2 \leq \mathrm{Kp} \leq 3^{+}$ & $4^{-} \leq \mathrm{Kp}<6$ \\
\hline Dawn (03:00-09:00 LT) & $6.6 \%$ & $25 \%$ & $46 \%$ & $92 \%$ \\
Noon (09:00-15:00 LT) & $5.0 \%$ & $41 \%$ & $65 \%$ & $100 \%$ \\
Dusk (15:00-21:00 LT) & $30 \%$ & $52 \%$ & $84 \%$ & $100 \%$ \\
Night (21:00-03:00 LT) & $23 \%$ & $48 \%$ & $86 \%$ & $100 \%$ \\
Average & $16 \%$ & $42 \%$ & $70 \%$ & $98 \%$ \\
\hline
\end{tabular}

are larger than those in the bins of 18:00-20:00 LT, 20:0022:00 LT and 22:00-24:00 LT, respectively. According to the drift theory, the Alfvén boundary should be day-night symmetric. This deviation may emerge from the fact that the ions on the day and night sides spend different times on their drift paths. When ions drift toward and around the Earth, they suffer from some loss mechanisms, which include coulomb scattering, particle-wave interaction and charge exchange. The longer an ion is exposed to these loss mechanisms, the higher the probability of its loss. Obviously, the ions on the day side spend more time in their drift paths than those on the night side. Therefore the ion flux on the day side are smaller than those on the night side in ion drift paths, enabling the IBIPS on the day side to shift outward.

During active times, the mean radial distance of IBIPS is basically smaller than $6.6 R_{\mathrm{E}}$ except in the sector of 04:0008:00 LT. The IBIPSs in the 18:00-20:00 LT bin are closest to the Earth and the mean radial distance in this bin is about $5.69 R_{\mathrm{E}}$. The IBIPS in the 04:00-06:00 LT bin is farthest to the Earth and the mean radial distance of IBIPS is about $6.9 R_{\mathrm{E}}$. Similarly, the IBIPS on the day side is farther from the Earth than that on the night side, but with only one exception in the sector of 04:00-08:00 LT.

The differences between the mean radial distances of IBIPS in 12 local time bins during quiet and active times are also given in the last column of Table 1. It can be found that the differences between two sets of mean radial distances of IBIPS are largest in the bins of 22:00-24:00 LT and 00:0002:00 LT. This means that when the strength of convection electric field increases, the inward shift of IBIPS is most significant on the night side.

The geosynchronous orbit, located at approximately 6.6 $R_{\mathrm{E}}$ geocentric distance in the geographical equatorial plane, is at the transition from the magnetotail plasma sheet to the storm-time ring current (e.g., Thomsen et al., 2003; Denton et al., 2005, 2006). Since the inner boundary of ion plasma sheet often passes the geosynchronous orbit $\left(6.6 R_{\mathrm{E}}\right)$ when it moves to the Earth in response to enhanced convection (Borovsky et al., 1998; Korth et al., 1999; Thomsen et al., 2003; Denton et al., 2005; and Lavraud et al., 2006), it is meaningful to make a survey of the percentage of IBIPS that can penetrate inside geosynchronous orbit. Table 2 gives the penetration ratios of IBIPS inside geosynchronous or- bit in four local time sectors for four Kp bins $\left(\mathrm{Kp}<0^{+}\right.$, $1^{-} \leq \mathrm{Kp}<2,2 \leq \mathrm{Kp}<3^{+}$and $4^{-} \leq \mathrm{Kp} \leq 6$. For each $\mathrm{Kp}$ bin, the penetration ratio of IBIPS of each sector is defined as the ratio of the number of IBIBS inside geosynchronous orbit to the total number of IBIPS in each sector. The penetration ratios of IBIPS in the dusk and night sectors are almost same. They are larger than those in the dawn and noon sectors. The penetration ratio of IBIPS increases with increasing Kp. During very quiet times $\left(\mathrm{Kp} \leq 0^{+}\right), 16 \%$ of IBIPSs can penetrate inside the geosynchronous orbit. However for $2 \leq \mathrm{Kp} \leq 3^{+}$, $70 \%$ of IBIPSs can penetrate inside the geosynchronous orbit. For $4^{-}<\mathrm{Kp} \leq 6$. they are all inside the geosynchronous orbit except only an exception in the dawn sector.

However, the observations also show that even during quiet times, a few IBIPS can still penetrate inside geosynchronous orbit and on the contrary. There are several reasons that may be responsible for this deviation. First the time history of particle drift motion can possibly cause this phenomenon. For example, Kp could have been high prior to the crossing of IBIPS by TC-1, pushed the IBIPS toward the Erath, then recovered quickly, leaving the IBIPS inward when $\mathrm{Kp}$ is low. Secondly, there may be some other factors that may influence the movement of IBIPS. Previous studies have found that besides the convection electric field represented by $\mathrm{Kp}$, solar wind conditions associated with large scale magnetosphere compression can also considerably influence the positions of the inner boundary of the plasma sheet (Lavraud et al., 2006) and enhanced ring current (Dandouras et al., 2009b). Thirdly, the time resolution of Kp index is $3 \mathrm{~h}$. Therefore the Kp index can not represent exactly the status of convection electric field at the time of IBIPS crossing by TC-1. Fourthly, some small scale electric field in the inner magnetosphere can also cause the local access of plasma sheet ions into the inner magnetosphere (Ganushkina et al., 2000, 2001).

Figure 4 shows the scatter plot of the inner boundary of the ion plasma sheet in the X-Y GSM plane detected by TC1 color-coded according to AE index (the strength of auroral electrojet). It seems that the radial distance of IBIPS only has a weak relation to the AE index. Many black and blue points $(\mathrm{AE}<200 \mathrm{nT})$ are located inside the geosynchronous orbit. In contrast, many green, yellow and even red points are outside the geosynchronous orbit. For example, on 26 June 


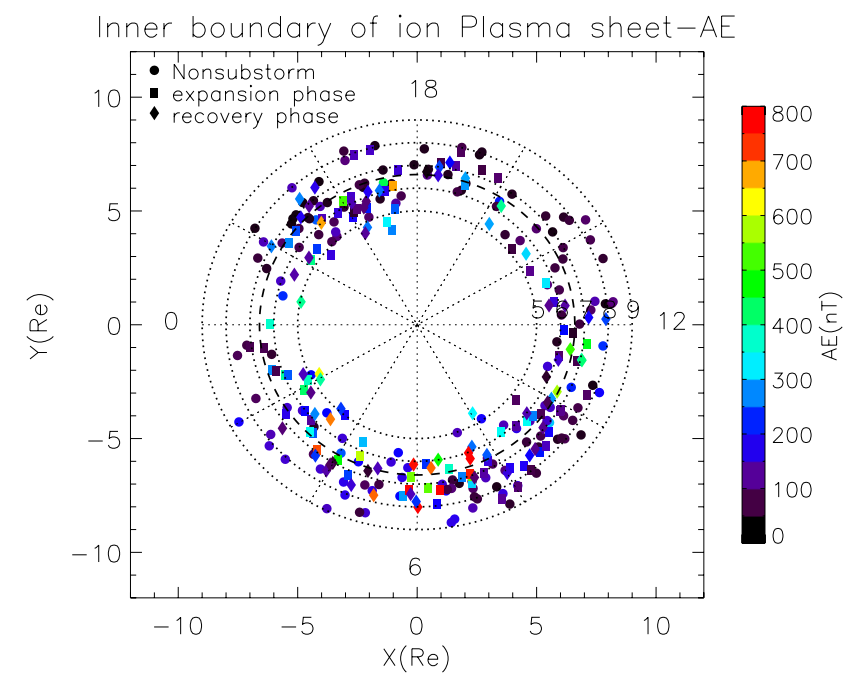

Fig. 4. The scatter plot of inner boundary of ion plasma sheet detected by TC-1 in the X-Y GSM plane color-coded according to AE index. The symbols of circle, square and diamond represent nonsubstorm, expansion and recovery phases of substorm, respectively.

2004, TC-1 crossed the IBIPS at 23:20 UT at radial distance of $8.01 R_{\mathrm{E}}$ (see the red square at $(x, y)=(0.03,-8.01) R_{\mathrm{E}}$ ). This crossing event occurred in an expansive substorm phase and the AE index reached $800 \mathrm{nT}$.

The weak relationship between radial distance of IBIPS and substorm AE index is also confirmed by the analysis of the penetration ratio of IBIPS inside geosynchronous orbit ordered by $\mathrm{AE}$ index. Table 3 gives the penetration ratio of IBIPS inside the geosynchronous orbit for different AE bins. The penetration ratio of IBIPS basically increases with the increase of AE index with only an exception in the noon sector. It can be found that even when AE is very low, the average penetration ratio in dusk and night sectors can still exceed $40 \%$. Comparing Table 3 and Table 2, we find that the IBIPS has a weaker relation with AE than that with Kp. This weak correlation between IBIPS and AE means that the movement of IBIPS is not closely related with substorm process, or in other words not closely related with real time $\mathrm{AE}$ index.

In order to reveal why at small AE values some IBIPS can still penetrate inside the geosynchronous orbit, we plot IBIPS at $\mathrm{AE}<70 \mathrm{nT}$ in the X-Y GSM plane color-coded according to Kp index (see Fig. 5). There are four IBIPSs with a radial distance less than $5.5 R_{\mathrm{E}} .:$ three on the dusk side and one on the dawn side. Two of them occurred in the non-substorm time and two in the expansion phase. All these four innermost IBIPSs have a Kp value larger than or equal to 2. This indicates that no matter how small the AE index is and what phase it is in, only if $\mathrm{Kp}$ is large enough, the IBIPS is still able to penetrate into geosynchronous orbit. This once again confirms the dominant role of the $\mathrm{Kp}$ index in determining the location of IBIPS.

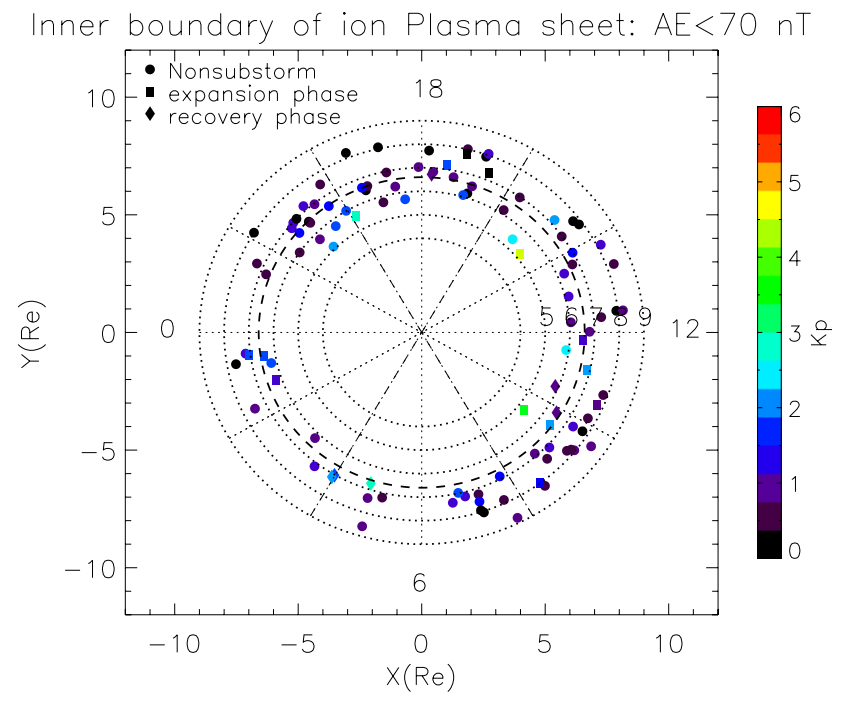

Fig. 5. The scatter plot of inner boundary of ion plasma sheet detected by TC- 1 in the X-Y GSM plane for AE $<70 \mathrm{nT}$ color-coded according to Kp index. The symbols of circle, square and diamond represent non-substorm, expansion phase and recovery phase, respectively.

Figure 6 shows the same dataset as plotted in Figs. 2 and 4 but now color-coded according to the Dst index (the strength of ring current). As in Fig. 4, the radial distance of IBIPS seems to have a weak relation to the Dst index. The IBIPSs with same or close colors are widespread in the radial direction from $5 R_{\mathrm{E}}$ to $9 R_{\mathrm{E}}$. Even during non-storm times, a large amount of IBIPS are located inside geosynchronous orbit. In addition, there is no obvious difference between the distributions of IBIPS in the main phase (square) and recovery phases (diamond). Table 4 shows the penetration ratio of IBIPS inside geosynchronous orbit for different Dst bins. The penetration ratio increases basically with increasing negative Dst with only an exception in the dusk sector. During the period of magnetospheric compression where Dst $>0,41 \%$ of IBIPS can penetrate into geosynchronous orbit. In the presence of large ring current $(-100 \mathrm{nT}<\mathrm{Dst}<-30 \mathrm{nT})$, the penetration ratio of IBIPS increases to $66 \%$. Thus even when Dst $<-30 \mathrm{nT}$, a lager amount of IBIPS remains outside geosynchronous orbit in the dawn, noon and dusk sectors. All these observations indicate that the positions of IBIPS only have a weak correlation with the ring current index.

In order to reveal further the relations of IBIPS with $\mathrm{Kp}$, Dst and AE indexes, we calculated the correlation coefficient between the radial distance of IBIPS $R_{i}$ and geomagnetic activity indexes for four local time sectors (see Table 5). The average correlation coefficient between $R_{i}$, and $\mathrm{Kp}$ is -0.58 while the average correlation coefficient between $R_{i}$, and $\mathrm{AE}$ (Dst) is only $-0.29(0.17)$. Here, the correlation is negative, meaning that the decrease of $R_{i}$ corresponds to an increase of 
Table 3. The penetration ratio $\rho$ of IBIPS inside geosynchronous orbit in four local time sectors for different AE bins.

\begin{tabular}{lcccc}
\hline LT sectors & $0 \leq \mathrm{AE}<50$ & $50 \leq \mathrm{AE}<150$ & $150 \leq \mathrm{AE}<250$ & $250 \leq \mathrm{AE}<800$ \\
\hline Dawn (03:00-09:00 LT) & $5 \%$ & $29 \%$ & $49 \%$ & $56 \%$ \\
Noon (09:00-15:00 LT) & $29 \%$ & $47 \%$ & $43 \%$ & $71 \%$ \\
Dusk (15:00-21:00 LT) & $40 \%$ & $64 \%$ & $73 \%$ & $85 \%$ \\
Night (21:00-03:00 LT) & $42 \%$ & $57 \%$ & $68 \%$ & $82 \%$ \\
Average & $29 \%$ & $49 \%$ & $58 \%$ & $73 \%$ \\
\hline
\end{tabular}

Table 4. The penetration ratio $\rho$ of IBIPS inside geosynchronous orbit in four local time sectors for different Dst bins.

\begin{tabular}{lcccc}
\hline LT sectors & $0 \leq$ Dst $<30$ & $-15 \leq$ Dst $<0$ & $-30 \leq$ Dst $<-15$ & $-100 \leq$ Dst $<-30$ \\
\hline Dawn (03:00-09:00 LT) & $23 \%$ & $38 \%$ & $50 \%$ & $50 \%$ \\
Noon (09:00-15:00 LT) & $40 \%$ & $42 \%$ & $44 \%$ & $57 \%$ \\
Dusk (15:00-21:00 LT) & $46 \%$ & $66 \%$ & $52 \%$ & $70 \%$ \\
Night (21:00-03:00 LT) & $54 \%$ & $56 \%$ & $64 \%$ & $87 \%$ \\
Average & $41 \%$ & $50 \%$ & $53 \%$ & $66 \%$ \\
\hline
\end{tabular}

Table 5. The correlation coefficients $r$ between radial distances of IBIPS $R_{i}$ and geomagnetic activity indices $\mathrm{Kp}, \mathrm{AE}$ and Dst.

\begin{tabular}{lccc}
\hline LT sectors & $r\left(\mathrm{Kp}, R_{i}\right)$ & $r\left(\mathrm{AE}, R_{i}\right)$ & $r\left(\mathrm{Dst}, R_{i}\right)$ \\
\hline Dawn (03:00-09:00 LT) & -0.72 & -0.54 & 0.35 \\
Noon (09:00-15:00 LT) & -0.55 & -0.24 & 0.19 \\
Dusk (15:00-21:00 LT) & -0.54 & -0.15 & 0.04 \\
Night (21:00-03:00 LT) & -0.54 & -0.24 & 0.14 \\
Average & -0.58 & -0.29 & 0.18 \\
\hline
\end{tabular}

$\mathrm{Kp}$ (or AE). The correlation coefficients are local time dependent. The correlation between $R_{i}$ and $\mathrm{Kp}$ index is high in the night sector and moderate in other three sectors. The correlation between $R_{i}$ and $\mathrm{AE}$ index is moderate in the night sector and low in other three sectors. The correlation between $R_{i}$ and Dst index is low in the night sector and negligible in other three sectors.

A common feature of three correlation coefficients is that they are all largest in the night sector. Particularly, $R_{i}$ and $\mathrm{Kp}$ are highly correlated $(r=-0.72)$ in the night sector. Such a high correlation between $R_{i}$ and $\mathrm{Kp}$ means that the radial distance of IBIPS $R_{i}$ in the night sector has the fastest response to the $\mathrm{Kp}$ index and can be organized by Kp index. The higher correlations in the night sector may be due to the fact that the ions in the night sector spend the least time on their drift paths and therefore suffer from least loss while the loss mechanisms are related with other parameters in the inner magnetosphere, such as the intensity of electromagnetic waves and the density of neutral particles in the exosphere.

\section{Conclusions and discussions}

In this paper, based on a dataset of 310 crossing events of inner boundary of ion plasma sheet detected by TC-1 from 2004 to 2006, we for the first time show the observational distribution of inner boundary of ion plasma sheet in the equatorial plane. The IBIPS has dawn-dusk asymmetry. During the quiet times the IBIPS is farthest to the Earth in the 06:00-08:00 LT bin and the mean radial distance of IBIPS in this bin is $7.64 R_{\mathrm{E}}$. The IBIPS is closest to the Earth in the 18:00-20:00 LT bin and the mean radial distance of IBIPS is $6.50 R_{\mathrm{E}}$. These characteristics of IBIPS are consistent with the Alfvén boundary of plasma sheet ions expected from drift theory. The mean radial distances of IBIPS in the bins of 16:00-18:00 LT, 14:00-16:00 LT and 12:00-14:00 LT are larger than those in the bins of 18:00-20:00 LT, 20:0022:00 LT and 22:00-24:00 LT, respectively. This day-night asymmetry is not consistent with the expectations of a simple, steady Volland Stern type of convection pattern. This deviation may be due to the fact that the ions on the dayside are exposed more time to loss mechanisms.

The radial distance of IBIPS decrease generally with the increase of $\mathrm{Kp}$ index. The mean radial distance of IBIPS is basically larger than $6.6 R_{\mathrm{E}}$ during quiet times with only an exception in the 18:00-20:00 LT bin while during active times, the mean radial distance of IBIPS is basically smaller than $6.6 R_{\mathrm{E}}$ except in the sector of 04:00 LT-08:00 LT. When the strength of convection electric field increases, the inward shift of IBIPS is most significant on the night side (22:0002:00 LT). For $\mathrm{Kp}<0^{+}$, on average $16 \%$ of IBIPS penetrate inside the geosynchronous orbit while for $2 \leq \mathrm{Kp} \leq 3^{+}$, however, $70 \%$ of IBIPSs penetrate inside the geosynchronous 
Inner boundary of ion plasma sheet--Dst

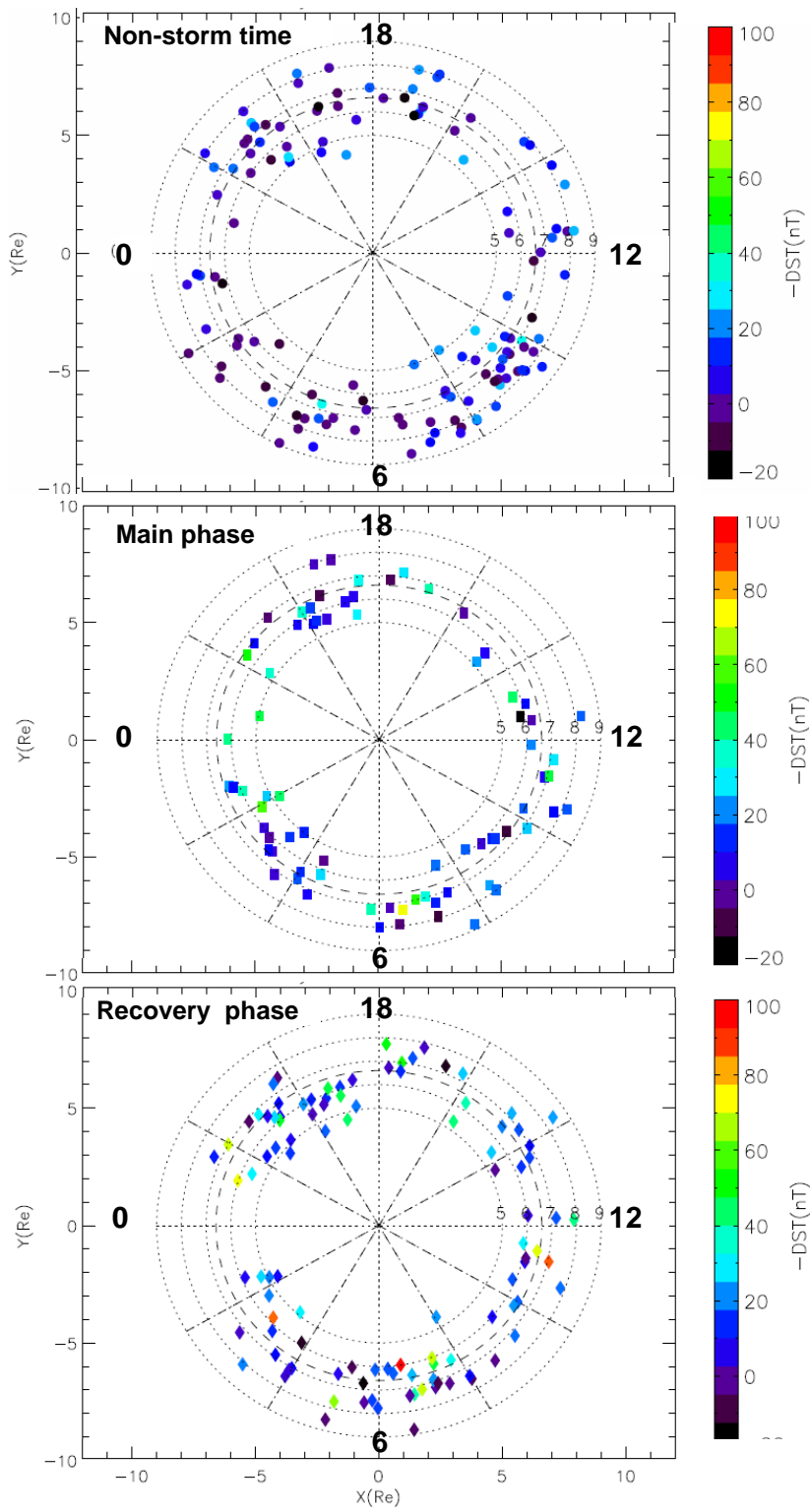

Fig. 6. The scatter plot of inner boundary of ion plasma sheet detected by TC-1 in the X-Y GSM plane color-coded according to Dst index.

orbit. For $4^{-}<\mathrm{Kp} \leq 6$, all IBIPSs are located inside the geosynchronous orbit except for one exception in the dawn sector. These observations indicate that Kp plays a key role in determining the position of the IBIPS.

The characteristics of IBIPS presented here are consistent with previous observations of hot ions at geosynchronous orbit. Korth et al. (1999) reported that MPA on board geosynchronous satellite LANL observed plasma sheet ions more frequently on dusk side than on the dawn side (see Plate 2 in Korth et al., 1999). Friedel et al. (2001) projected the data of Polar HYDRA to the equatorial plane and obtained sim- ilar results. It is obvious that this result is consistent with the dawn-dusk symmetry of IBIPS, i.e. the radial distance of IBIPS on the dusk side is smaller than that on the dawn side. The shorter radial distances of IBIPS on the dusk side allow the plasma sheet ions to have a more frequent access at the dusk side geosynchronous orbit. Zhang et al. (2006) reported that the plasma sheet ions (intermediately hot ions in their paper) can have more frequent access to geosynchronous orbit in the pre-midnight sector and the afternoon sector. Denton et al. (2005) reported that the temperature of hot protons $(100 \mathrm{eV}-45 \mathrm{keV})$ has its peak between 12:00 and 24:00 LT. As stated by Korth et al. (1999), the temperature profiles reflect the accessibility of hot particles on geosynchronous orbit.

All these observations indicate that the Kp index plays a key role in determining the position of IBIPS. This conclusion is also confirmed by correlation analysis. The average correlation coefficient between $R_{i}$, and $\mathrm{Kp}$ is -0.58 while the correlation coefficient between $R_{i}$, and $\mathrm{AE}$ (Dst) is only -0.29 (0.17). Particularly, the radial distance of IBIPS $R_{i}$ and $\mathrm{Kp}$ is highly correlated in the night sector, suggesting the radial distance of IBIPS has the fastest response to the Kp index in the night sector and can be organized by Kp index. It is worth noting that the correlation coefficient between $R_{i}$, and $\mathrm{AE}$ in the night sector reached -0.54 , implying that $R_{i}$ and $\mathrm{AE}$ index in the night sector are not weakly correlated but moderately correlated, which may be due to the effect of substorm ion injection which is stronger in the night sector.

The weak correlation between $R_{i}$, and AE/Dst indicate that the position of IBIPS has weak relation with substorm/storm process. However it does not mean that the inner boundary of plasma sheet does not move during substorms and storm. Previous reports once showed that the inner boundary of plasma sheet can move rapidly during substorm (Runov et al., 2008) and storm (Wang et al., 2008). In fact, three magnetic activity indics $\mathrm{Kp}, \mathrm{AE}$ and Dst are not completely unrelated. The auroral electrojet index AE index is obtained from a number of stations distributed in local time in the latitude region which is typical of the Northern Hemisphere auroral zone. The equatorial ring current index Dst is obtained from magnetometer stations near the equator. The planetary magnetic index $\mathrm{Kp}$ index is obtained from a network of magnetometer stations at mid-latitudes, which can record the superposed effects of the auroral electrojet current system, the magnetospheric ring current and field-aligned currents that connect the ionosphere to the magnetosphere. Although the precise relations among these three indices are still unknown, the increases of AE and -Dst can more or less lead to an increase of $\mathrm{Kp}$. We calculated the correlation coefficients between $\mathrm{Kp}$ and $\mathrm{AE}$ (Dst). It is not surprising to find that $\mathrm{Kp}$ and $\mathrm{AE}$ (-Dst) are moderately correlated, and the correlation coefficient between $\mathrm{Kp}$ and $\mathrm{AE}$ (-Dst) is 0.62 (0.45). Wang et al. (2008) reported that the inner edge of the ion plasma sheet near dusk moved from $R \sim 6 R_{\mathrm{E}}$ during the pre-storm quiet time to $R \sim 3.5 R_{\mathrm{E}}$ during the main 
phase, and then moved outward during the recovery phase. This movement of inner edge of plasma sheet may be owing to the variations of convection electric field, since Kp, an indicator of the strength of magnetospheric convection, is 1.33 prior to main phase, 4.0 during main phase and early recovery phase and 1.0 during late recovery phase, respectively.

Finally, there are two issues which may affect the analysis here. The first is the threshold value of temperature $2 \mathrm{keV}$ in determining IBIPS. This value is usually located between the middle of the increasing temperature slope and the first peak of temperature. If we chose $1 \mathrm{keV}$ as the threshold values, the position of IBIPS will become closer to the Earth by $0.1-$ $0.3 R_{\mathrm{E}}$. The second is the temperature calculation. The ideal concept of temperature is only valid for a Maxwell velocity distribution. For some of the IBIPS crossing events studied here, there are two coexisting populations: hot plasma sheet ions and cold plasmaspheric ions. In such cases, the temperature derived here is a density weighted mean of the temperature of the two populations. However since the plasmapause is usually located earthward of the plasma sheet and move earthward together with the inner boundary of plasma sheet under an enhanced convection electrical field, the influence of plasmaspheric ions to our results is limited.

It must be pointed out that in our work, there is an apparent shortage of cases of IBIPS during very active times. This is caused by the fact that in the operation plan of HIA/TC-1, the HIA/TC-1 is powered off for the purpose of not being damaged by radiation belt energetic particles. Just during very active times, the IBIPS often penetrate deeply into the radiation belt. Therefore the analysis presented in this study is valid only for quiet to moderate geomagnetic activity.

In this work, we mainly focused on the relations between inner boundary of ion plasma sheet (IBIPS) and geomagnetic activity indices $\mathrm{Kp}, \mathrm{AE}$ and Dst. In fact the solar wind conditions can also influence the positions of IBIPS (Lavraud et al., 2006). Lemon and O'Brien (2008) once established a solar wind driven model of geosynchronous plasma moments. So the further extension of this work is to analyze the influence of solar wind conditions to the positions of IBIPS.

Acknowledgements. This work was supported by NSFC Grant 40931054, 973 program 2011CB811404, 863 program 2008AA12A216, and the Specialized Research Fund for State Key Laboratories.

Topical Editor I. A. Daglis thanks M. Thomsen and another anonymous referee for their help in evaluating this paper.

\section{References}

Birn, J., Thomsen, M. F., Borovsky, J. E., Reeves, G. D., McComas, D. J., and Belian, R. D.: Characteristic plasma properties during dispersionless substorm injections at geosynchronous orbit, J. Geophys. Res., 102, 2309-2324, 1997.

Borovsky, J. E., Thomsen, M. F., Elphic, R. C., Cayton, T. E., and McComas, D. J.: The transport of plasma sheet material from the distant tail to geosynchronous orbit, J. Geophys. Res., 103, 20297-20331, 1998.

Carr, C., Brown, P., Zhang, T. L., Gloag, J., Horbury, T., Lucek, E., Magnes, W., O’Brien, H., Oddy, T., Auster, U., Austin, P., Aydogar, O., Balogh, A., Baumjohann, W., Beek, T., Eichelberger, H., Fornacon, K.-H., Georgescu, E., Glassmeier, K.-H., Ludlam, M., Nakamura, R., and Richter, I.: The Double Star magnetic field investigation: instrument design, performance and highlights of the first year's observations, Ann. Geophys., 23, 2713 2732, doi:10.5194/angeo-23-2713-2005, 2005.

Chen, M. W., Lyons, L. R., and Schulz, M.: Simulations of phase space distributions of storm time proton ring current, J. Geophys. Res., 99, 5745-5759, 1994.

Dandouras, I., Cao, J. B., and Vallat, C.: Energetic ion dynamics of the inner magnetosphere revealed in coordinated ClusterDouble Star observations, J. Geophys. Res., 114, A01S90, doi:10.1029/2007JA012757, 2009a.

Dandouras, I., Rème, H., Cao, J. B., and Escoubet, P.: Magnetosphere response to the 2005 and 2006 extreme solar events as observed by the Cluster and Double Star spacecraft, Adv. Space Res., , 43(4), 618-623, 2009b.

Denton, M. H., Thomsen, M. F., Korth, H., Lynch, S., Zhang, J. C., and Liemohn, M. W.: Bulk plasma properties at geosynchronous orbit, J. Geophys. Res., 110, A07223, doi:10.1029/2004JA010861, 2005.

Denton, M. H., Thomsen, M. F., Lavraud, B., Henderson, M. G., Skoug, R. M., Funsten, H. O., Jahn, J. M., Pollock, C. J., and Weygand, J. M.: Transport of plasma sheet material to the inner magnetosphere, Geophys. Res. Lett., 34, L04105, doi:10.1029/2006GL027886, 2007.

Ding, W. Z., Cao, J. B., Zeng, L., Wang, Y., and Yang, J. Y.: Simulation studies of plasma sheet ion boundary, Chinese Journal of Geophysics, 53, 1505-1514, 2010.

Ebihara, Y., Fok, M.-C., Sazykin, S., Thomsen, M. F., Hairston, M. R., Evans, D. S., Rich, F. J., and Ejiri, M.: Ring current and the magnetosphere-ionosphere coupling during the superstorm of 20 November 2003. J. Geophys. Res., 110, A09S22, doi:10.1029/2004JA010924, 2005.

Fok, M.-C., Moore, T. E., and Greenspan, M. E.: Ring current development during storm main phase, J. Geophys. Res., 101, 15311-15322, 1996.

Friedel, R. H. W., Korth, H., Henderson, H. G., Thomsen, M. F. and Scudder, J. D.: Plasma sheet access to the inner magnetosphere, J. Geophys. Res., 106, 5845-5858, doi:10.1029/2000JA003011, 2001.

Ganushkina, N. Yu., Pulkkinen, T. I., Sergeev, V. A., Kubyshkina, M. V., Baker, D. N., Turner, N. E., Grande, M., Kellett, B., Fennell, J., Roeder, J., Sauvaud, J.-A., and Fritz, T. A.: Entry of plasma sheet particles into the inner magnetosphere as observed by Polar/CAMMICE, J. Geophys. Res., 105, 2520525219, doi:10.1029/2000JA900062, 2000.

Ganushkina, N. Y., Pulkkinen, T. I., Bashkirov, V. F., Baker, D. N., and Li, X.: Formation of intense nose structures, Geophys. Res. Lett., 28(3), 491-494, doi:10.1029/2000GL011955, 2001.

Ganushkina, N. Yu., Pulkkinen, T. I., and Fritz, T.: Role of substorm-associated impulsive electric fields in the ring current development during storms, Ann. Geophys., 23, 579-591, doi:10.5194/angeo-23-579-2005, 2005.

Jordanova, V. K., Farrugia, C. J., Janoo, L., Quinn, J. M., Torbert, 
R. B., Ogilvie, K. W., Lepping, R. P., Steinberg, J. T., McComas, D. J., and Belian, R. D.: October 1985 magnetic cloud and accompanying storm activity: Ring current evolution, J. Geophys. Res., 103, 79-92, 1998.

Jordanova, V. K. and Miyoshi, Y.: Relativistic model of ring current and radiation belt ions and electrons: initial results, Geophys. Res. Lett., 32, L14104, doi:10.1029/2005GL023020, 2005.

Kerns, K. J., Hardy, D. A., and Gussenhoven, M. S.: Modeling of convection boundaries seen by CRRES in $120 \mathrm{eV}$ to $28 \mathrm{keV}$ particles, J. Geophys. Res., 99, 2403-2414, 1994.

Korth, H. and Thomsen, M. F.: Plasma sheet access to geosynchronous orbit: Generalization to numerical global field models, J. Geophys. Res., 106, 29665-29667, 2001.

Korth, H., Thomsen, M. F., Borovsky, J. E., and McComas, D. J.: Plasma sheet access to geosynchronous orbit, J. Geophys. Res., 104, 25047-25061, 1999.

Kozyra, J. U., Jordanova V. K., Borovsky J. E., et al.: Effects of a high-density plasma sheet on ring current development during the November 2-6, 1993, magnetic storm, J. Geophys. Res., 103, 26285-26306, 1998.

Lavraud, B., Thomsen, M. F., Wing, S., Fujimoto, M., Denton, M. H., Borovsky, J. E., Aasnes, A., Seki, K., and Weygand, J. M.: Observation of two distinct cold, dense ion populations at geosynchronous orbit: local time asymmetry, solar wind dependence and origin, Ann. Geophys., 24, 3451-3465, doi:10.5194/angeo-24-3451-2006, 2006.

Lemon, C. L. and O'Brien, T. P.: A solar wind driven model of geosynchronous plasma moments, Adv. Space Res., 41(8), 1226-1233, 2008.

Liemohn, M. W., Ridley, A. J., Brandt, P. C., Gallagher, D. L., Kozyra, J. U., Ober, D. M., Mitchell, D. G., Roelof, E. C., and DeMajistre, R.: Parametric analysis of nightside conductance effects on inner magnetospheric dynamics for the 17 April 2002 storm, J. Geophys. Res., 110, A12S22, doi:10.1029/2005JA011109, 2005.

Li, X., Baker, D. N., Temerin, M., Reeves, G. D., and Belian, R. D.: Simulation of dispersionless injections and drift echoes of energetic electrons associated with substorms, Geophys. Res. Lett., 25, 3763-3766, 1998.

Liu, Z. X., Escoubet, P., and Cao, J. B.: A Chinese European Multiscale mission: the double star program, Multiscale Coupling of Sun-Earth Processes, edited by: Lui, A. T. Y., Kamide, Y., and Consolini, G., Elsevier, 509-514, 2005.

Maurice, S., Thomsen, M. F., and McComas, D. J.: Quiet time densities of hot ions at geosynchronous orbit, J. Geophys. Res., 103, 17571-17585, 1998.

McComas, D. J., Bame, S. J., Barraclough, B., Donart, J., Elphic, R., Gosling, J., Moldwin, M., Moore, K., and Thomsen, M.: Magnetospheric plasma analyzer: Initial 3-spacecraft observations from geosynchronous orbit, J. Geophys. Res., 98, 1345313465, 1993.

Rème, H., Aoustin, C., Bosqued, J. M., Dandouras, I., Lavraud, B., Sauvaud, J. A., Barthe, A., Bouyssou, J., Camus, Th., CoeurJoly, O., Cros, A., Cuvilo, J., Ducay, F., Garbarowitz, Y., Medale, J. L., Penou, E., Perrier, H., Romefort, D., Rouzaud, J., Vallat, C., Alcaydé, D., Jacquey, C., Mazelle, C., d’Uston, C., Möbius, E., Kistler, L. M., Crocker, K., Granoff, M., Mouikis, C., Popecki, M., Vosbury, M., Klecker, B., Hovestadt, D., Kucharek, H., Kuenneth, E., Paschmann, G., Scholer, M., Sckopke, N., Seiden- schwang, E., Carlson, C. W., Curtis, D. W., Ingraham, C., Lin, R. P., McFadden, J. P., Parks, G. K., Phan, T., Formisano, V., Amata, E., Bavassano-Cattaneo, M. B., Baldetti, P., Bruno, R., Chionchio, G., Di Lellis, A., Marcucci, M. F., Pallocchia, G., Korth, A., Daly, P. W., Graeve, B., Rosenbauer, H., Vasyliunas, V., McCarthy, M., Wilber, M., Eliasson, L., Lundin, R., Olsen, S., Shelley, E. G., Fuselier, S., Ghielmetti, A. G., Lennartsson, W., Escoubet, C. P., Balsiger, H., Friedel, R., Cao, J.-B., Kovrazhkin, R. A., Papamastorakis, I., Pellat, R., Scudder, J., and Sonnerup, B.: First multispacecraft ion measurements in and near the Earth's magnetosphere with the identical Cluster ion spectrometry (CIS) experiment, Ann. Geophys., 19, 1303-1354, doi:10.5194/angeo19-1303-2001, 2001.

Rème, H., Dandouras, I., Aoustin, C., Bosqued, J. M., Sauvaud, J. A., Vallat, C., Escoubet, P., Cao, J. B., Shi, J., BavassanoCattaneo, M. B., Parks, G. K., Carlson, C. W., Pu, Z., Klecker, B., Moebius, E., Kistler, L., Korth, A., Lundin, R., and the HIA team: The HIA instrument on board the Tan Ce 1 Double Star near-equatorial spacecraft and its first results, Ann. Geophys., 23, 2757-2774, doi:10.5194/angeo-23-2757-2005, 2005.

Runov, A., Angelopoulos, V., Ganushkina, N., Nakamura, R., McFadden, J., Larson, D., Dandouras, I., Glassmeier, K. H., and Carr, C.: Multi-point observations of the inner boundary of the plasma sheet during geomagnetic disturbances, Geophys. Res. Lett., 35, L17S23, doi:10.1029/2008GL033982, 2008.

Stern, D. P.: The motion of a proton in the equatorial magnetosphere, J. Geophys. Res., 80, 595-599, 1975.

Thomsen, M. F.: Why $\mathrm{Kp}$ is such a good measure of magnetospheric convection, Space Weather, 2, S11004, doi:10.1029/2004SW000089, 2004.

Thomsen, M. F., Korth, H., and Elphic, R. C.: Upper cutoff energy of the electron plasma sheet as a measure of magnetospheric convection strength, J. Geophys. Res., 107(A10), 1331, doi:10.1029/2001JA000148, 2002.

Thomsen, M. F., Borovsky, J. E., Skoug, R. M., and Smith, C. W.: Delivery of cold, dense plasma sheet material into the near-Earth region, J. Geophys. Res., 108(A4), 1151, doi:10.1029/2002JA009544, 2003.

Volland, H.: A semiempirical model of large-scale magnetospheric electric fields, J. Geophys. Res., 78, 171-180, 1973.

Wang, C.-P., Lyons, L. R., Angelopoulos, V., Larson, D., McFadden, J. P., Frey, S., Auster, H. U., and Magnes, W.: THEMIS observations of penetration of the plasma sheet into the ring current region during a magnetic storm, Geophys. Res. Lett., 35, L17S14, doi:10.1029/2008GL033375, 2008.

Wolf, R. A., Harel, M., Spiro, R. W., Voigt, G. H., Reiff, P. H., and Chen, C. K.: Computer simulation of inner magnetospheric dynamics for the magnetic storm of July 29, 1977, J. Geophys. Res., 87, 5949-5962, 1982.

Zhang, J.-C., Liemohn, M. W., Thomsen, M. F., Kozyra, J. U., Denton, M. H., and Borovsky, J. F.: A statistical comparison of hotion properties at geosynchronous orbit during intense and moderate geomagnetic storms at solar maximum and minimum, J. Geophys. Res., 111, A07206, doi:10.1029/2005JA011559, 2006. 